\title{
R\&D Landscape for Breast Cancer through Patent Documents
}

\author{
Adelaide M. S. Antunes ${ }^{1,2 *}$, Iolanda M. Fierro ${ }^{1}$, Rafaela Di Sabato Guerrante ${ }^{1}$, \\ Priscila Rohem dos Santos ${ }^{1}$, Flavia Maria Lins Mendes ${ }^{2}$ \\ ${ }^{1}$ National Institute of Industrial Property, Rio de Janeiro, Brazil; ${ }^{2}$ Federal University of Rio de Janeiro, Postgraduate Program in \\ Technology of Chemical \& Biochemical Processes, Rio de Janeiro, Brazil. \\ Email: *aantunes@inpi.gov.br
}

Received June $12^{\text {th }}, 2013$; revised July $10^{\text {th }}, 2013$; accepted July $18^{\text {th }}, 2013$

Copyright (C 2013 Adelaide M. S. Antunes et al. This is an open access article distributed under the Creative Commons Attribution License, which permits unrestricted use, distribution, and reproduction in any medium, provided the original work is properly cited.

\begin{abstract}
Cancer is a leading cause of death worldwide, and is estimated to be the cause of 13.1 million deaths in 2030. Breast cancer is the second cancer in the global mortality ranking, considering both sexes. Due to the burden of breast cancer worldwide, this paper aims to present an overview of the main R\&D efforts focusing on breast cancer treatment. Patents were retrieved from the Derwent Innovations Index ${ }^{\circledR}$, which has a specific code for pharmaceuticals related to breast cancer. A total of 423 patent documents filed in recent years were identified, of which 126 are exclusively for breast cancer, 169 for breast cancer and other cancers, and 128 are inventions related to the treatment of cancer and other diseases. The patent documents were classified into two large groups, the first of which had a predominance of claims for antibodies, proteins and polypeptides for use in medication production, while the second focuses on gene therapy, nucleotides and RNA. The country with the majority of priority patent applications was found to be the United States, followed by China and Japan.
\end{abstract}

Keywords: Patent; Breast Cancer; Treatment; R\&D Trends

\section{Introduction}

The aim of this work is to use the technological information contained in patents as a way of identifying research and development (R\&D) trends in biotechnological pharmaceuticals for breast cancer treatment.

One of the most reliable tools for appraising technology development in a given sector is patent mining, because thousands of new patent applications are filed every year around the world. The scope and level of detail required for protection to be conferred on a given innovation means that $70 \%$ of all technical documentation produced in the world is only contained in patents and is not published in any other form. Each patent document should describe the state-of-the-art in a given area, report on existing problems, and suggest novel solutions to be granted protection by patent [1].

According to the Frascati Manual, patents and scientific publications serve as first-generation indicators of the outputs of innovation activity. In this paper we considered the Organization for Economic Co-Operation and

\footnotetext{
"Corresponding author.
}

Development (OECD, 1963) definition for R\&D activities. This definition states R\&D as all creative work undertaken on a systematic basis to increase the stock of scientific and technical knowledge, including knowledge of man, culture and society and the use of this knowledge to devise new applications [2]. Patent documents are valuable and unique source of data on technological effort, which is an aspect of innovative activity.

The analysis of patents from a given sector can serve different purposes, including: 1) to demonstrate growth prospects, if the number of patent applications filed over a particular time series is examined; 2) to identify patent assignees, thereby demonstrating market concentration patterns; 3) to identify what kinds of technology are being developed by making qualitative evaluations of the claims made in the patent documents; and 4) to identify technology trends [3].

It is well known that in the pharmaceuticals sector potentially important technologies tend to be protected by patents.

The importance of this kind of analysis resides in the fact that decisions about government investments in the 
development of new products and/or processes, the creation of partnerships for joint R\&D activities, and technology transfer agreements are in many cases related to the existence of patents.

\section{Breast Cancer}

According to World Health Organization data, breast cancer is the main form of cancer in women, but it can also affect men. In 2010, it is estimated that 1.5 million people were diagnosed with breast cancer [4]. If compared with all cancers that affect both sexes, it comes second for mortality, accounting for 458,000 deaths in 2008, as can be seen from Figure 1.

Considering the USA and Brazil as two representative countries from the Americas, it can be observed that in the United States it is estimated that 232,340 women will be diagnosed with breast cancer and 39,620 women will die of the disease in 2013. In Brazil, the estimated number of new cases in 2012 was 52,680, while 2010 data show that breast cancer was responsible for 12,852 deaths, of which 147 were of men and 12,705 of women [5].

Breast cancer is the form of cancer that most afflicts females, accounting for $22 \%$ of all new cancer cases each year. Its prognosis is relatively good provided it is diagnosed early. Worldwide, average survival after five years is $61 \%$. In Brazil, the mortality rate for breast cancer is still high, but probably because the disease still tends to be diagnosed at an advanced stage [5]. This is consistent with international data, which report that about $70 \%$ of all cancer deaths occur in low- and middle-income countries [6].

According to the National Cancer Institute in the United States, the most common type of breast cancer is ductal carcinoma, which begins in the cells of the ducts. Cancer that begins in the lobes or lobules is called lobular carcinoma and is more often found in both breasts than are other types of breast cancer. Inflammatory breast cancer is an uncommon type of breast cancer in which the breast is warm, red, and swollen [7].

Biotechnology is a powerful presence in healthcare. In its report entitled "Genomics and Global Health", the World Health Organization highlights genomics and pro- teomics as promising sources of breakthroughs for the treatment, diagnosis and prevention of several diseases [8].

Biotechnology refers to a set of enabling technologies whose common denominator is the use of biotech cells or molecules. It would also be fair to say that this area has three conceptual hallmarks which could arguably be expressed as generations, especially the advances that have led from fermentation processes to the most advanced cloning, enzyme and genome engineering techniques. Meanwhile, biotechnology R\&D is geared towards products, such as monoclonal antibodies, or technologies, such as gene therapy.

The aim of this study is to present the current global R\&D landscape for biotechnological medications for breast cancer treatment by investigating patent documents filed in recent years.

\section{Methodology}

The Derwent Innovations Index ${ }^{\circledR}$ was selected as the source of patents to this study. It is an internationally recognized database that facilitates the retrival of patent applications for future analysis, and has its own classifications, or manual codes, which classify technology knowledge into different areas. Since 2005, it has had a specific code for pharmaceuticals related to breast cancer treatment, B14-H01D1. As such, this is the year that was adopted as the starting point for the patent document search in this study, also bearing in mind that the main medical applications of modern biotechnology started to appear in the new millennium.

This search was combined with a search using the International Patent Classification (IPC) so as to ensure that no patent documents were overlooked. Providing a classification of industrial property, this system is the outcome of international agreements between different countries. Its main goal is to supply an effective means of retrieving documents so that the criterion of novelty can be appraised and the status of technology in different fields can be assessed. It also serves as a basis for the preparation of industrial property statistics, which in
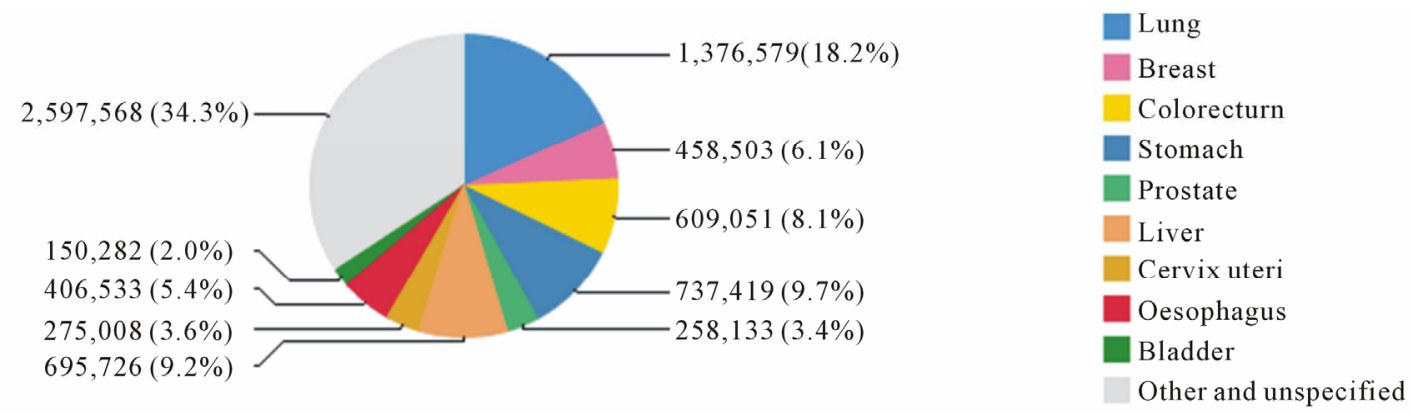

Figure 1. Mortality for different types of cancer in both sexes, according to WHO data [4]. 
turn permit the evaluation of technology developments in different areas. As such, for this study, a search was made of patent applications filed for medications (A61K), therapeutic activity (A61P) and biotechnology (C12N).

The result of the combined survey of the Derwent Innovations Index ${ }^{\circledR}$ Classification (Manual Code) and the IPC yielded 423 patent documents filed and published in the world about biotech medications for use in breast cancer treatment. The next stage was to conduct a qualitative analysis of the uses, claims, novelty, activity and mechanism of action described in the documents to identify technology trends.

\section{Results and Discussion}

Having read all 423 patent documents, it became clear that not all of them dealt exclusively with technologies for breast cancer treatment. As such, the documents were divided into three categories: 1) patents exclusively for breast cancer (126 patent documents, or 30\%); 2) patents for breast cancer and other cancers, particularly lung cancer, colon cancer and prostate cancer (169 patent documents, or $40 \%$ ); and 3) patents for breast cancer, other cancers and other diseases, including diabetes, rheumatoid arthritis, Alzheimer's disease, Huntington's disease, Parkinson's disease, multi-infarct dementia, mixed Alzheimer/multi-infarct dementia and hypothyroidism (128 patent documents, or 30\%) (Figure 2).

Another observation made from the perusal of the documents was that amongst the claims for breast cancer treatment, there were many that were also for its prevention and/or diagnosis. This led to another classification of the 423 patent documents: 241 were just for treatment; 29 were just for diagnosis, nine were just for prevention, 65 were for treatment and prevention, 63 were for treatment and diagnosis, and 16 were for treatment, diagnosis and prevention. This is shown in Figure 2. One example is the use of monoclonal antibodies to make diagnosis kits of tumors or pre-cancerous stem cells. When looking at the diagnosis-related technologies, it was found that some of the patent documents also made mention of prognosis, such as the possibility of predicting the continuation of treatment by detecting expression levels of a set of genes or of a particular gene (estrogen receptor) $[9,10]$.

Patent assignees, which are the holders of the rights to the patented technology, may choose to patent their invention in different countries. In this study, the breakdown of the patents by country only considered the priority patent applications, i.e. the first country in which the patent applications were filed (see Figure 3).

In Figure 3, it can be seen that most of the priority patent applications were made in the United States (251). This country is followed by China and Japan, with 46 and 45 priority applications each, respectively, while

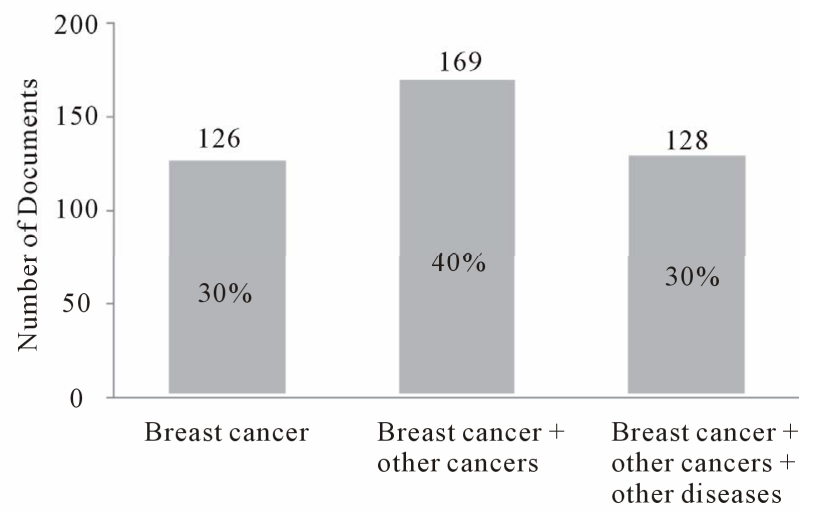

(a)

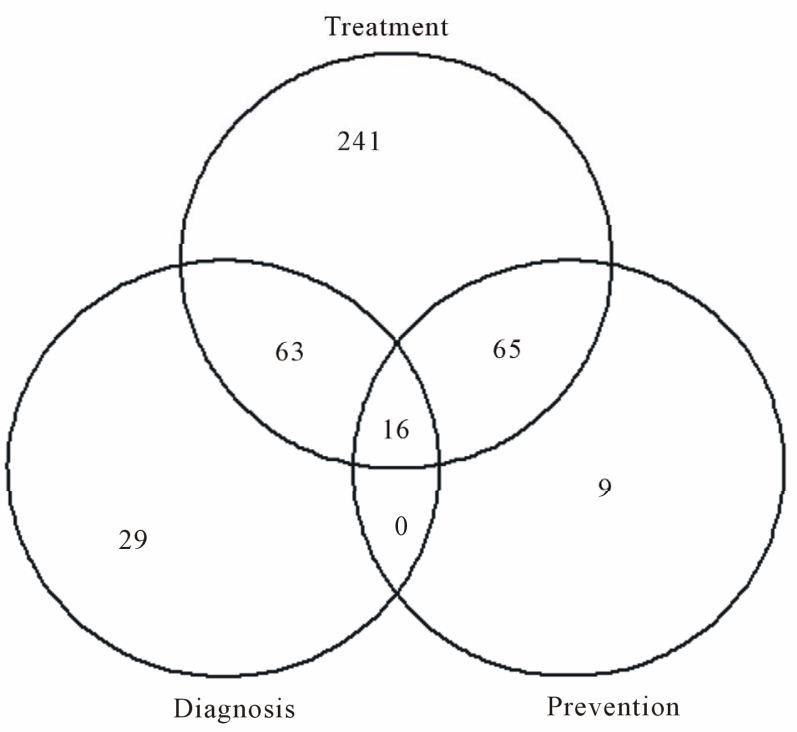

(b)

Figure 2. Graphic representation of patent documents. Documents divided by categories; Documents divided by utilization.

Europe has a total of 58 priority applications, with the top country in the bloc being the UK, with 21 .

By analyzing the "claims", "novelty", "activity" and "mechanism of action" fields from the patent applications, it was possible to divide the $\mathrm{R} \& \mathrm{D}$ trends they contain into two major groups of biotechnology entities, as shown in Table 1.

There were a few documents ( $7 \%$ of the total) which did not fit into either of these two groups. These patents applications are for active ingredients extracted from plants, agents acting in gene transfer (polymers) and cell therapy (using chemical compounds or stem cells).

The patents identified were then divided by their application (for breast cancer, for breast cancer and other cancers, or for breast cancer, other cancers and other diseases) into the two groups of biotech entities. The results of this breakdown can be seen in the following figures. 


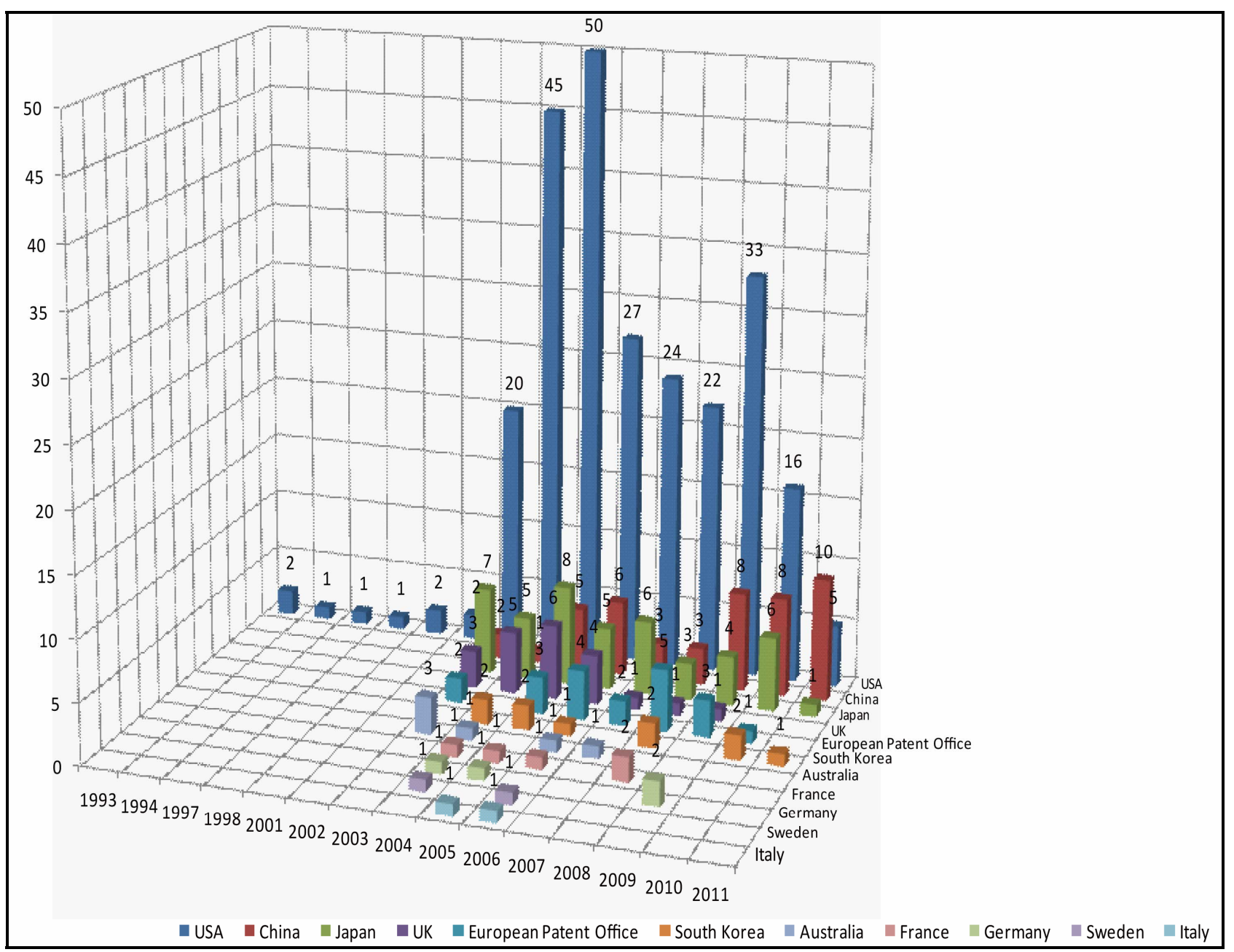

Figure 3. Distribution of patent applications over time by country.

Table 1. Main biotechnological entities in patents for breast cancer.

\begin{tabular}{cc}
\hline Group 1 & Group 2 \\
\hline & Nucleotides, Oligonucleotides and \\
Antibodies (Monoclonal or & Polynucleotides-47 \\
Recombinant)—83 & Genes and Fusion Genes-28 \\
Proteins (Fusion or & RNA, RNAi, siRNA, Recombinant \\
Recombinant)—74 & RNA and miRNA-42 \\
Peptides and Polypeptides—57 & DNA, DNA Microarray and \\
Enzymes_4 & Recombinant DNA-19 \\
Amino acids-3 & Nucleic Acid-18 \\
Recombinant Albumin-1 & Recombinant Vector-12 \\
Recombinant Toxin-1 & Transgenic Microorganism-4 \\
& Gene Promoter-1 \\
\hline
\end{tabular}

The entities from Group 1 cited in the patent applications exclusively for breast cancer treatment involve primarily protein-based medications, followed by peptides and monoclonal antibodies, while from Group 2 there is a broader array of biotech entities, made up primarily of Genes and Fusion Genes, RNA, Nucleotides (oligonucleotides and polynucleotides) and DNA.

Around $85 \%$ of these 126 patent applications relating specifically to breast cancer were filed first in the United States or Asia. The 64 priority patent applications filed in the USA were mostly filed by residents: $52 \%$ by universities and/or research centers, $38 \%$ by companies, and $10 \%$ by individuals. The leading assignee is the University of California, with nine patent applications.

Turning to the biotech entities, $58 \%$ of the patent applications made in the USA fit into Group 2, and are primarily for genes, fusion genes, RNAi and oligonucleotides. The $42 \%$ from Group 1 are primarily for proteins, peptides and monoclonal antibodies. This indicates a potential trend for future medications to include oncogene blocking and/or the replacement of altered tumor suppressor genes.

Gene therapy is one of the main mechanisms used in the new technologies to optimize breast cancer treatment. 
What RNAi does is to silence the expression of genes that encode proteins implicated in carcinogenesis. One example is patent application US2012004278, which comprises administering to a subject with metastatic cancer an amount of a RNA interference inhibitor of HOTAIR long non-coding RNAs (lincRNA) levels or function, or an amount of an RNAi inhibitor to inhibit HOTAIR LincRNA expression from the HOTAIR gene. Basically, through this technology it is possible to silence any kind of gene, including genes that are not yet treatable using conventional drugs [11].

RNAi technology can also be used to identify cancer more quickly than other technologies. Patent application US2012010090 is for an siRNA composition which reduces the expression of the nucleic acid sequence A5657, B9769, or C7965, in view of the fact that diagnosing breast cancer or a predisposition to developing breast cancer in a subject comprises determining a level of expression of a breast cancer-associated gene in a patient-derived biological sample selected from A5657, B9769, and C7965, where an increase in the sample expression level as compared to a normal control level of the gene indicates that the subject suffers from or is at risk of developing breast cancer [12].

As oligonucleotides are complementary to mRNA, they are used to inhibit the translation of a target protein that could be expressed defectively. In patent application US2010331390, for instance, the aim is to modulate the level of a target gene mRNA, with an antisense oligonucleotide containing 15 - 30 nucleobases, where the antisense oligonucleotide reduces the level of apolipoprotein B mRNA [13].

Different proteins and peptides have been tested with the aim of manipulating the expression of specific genes in cancer cells without the transfer of genetic material. Most of the patent applications encountered involve polypeptides, one example being patent application US2009202587, which shows a recombinant polypeptide comprising a polypeptide (P1) encoded by a defined sequence of 294 base pairs (SEQ ID NO: 23) given in the specification, linked to a non-high molecular weight melanoma-associated antigen (HMW-MAA) polypeptide [14]. Another important target of cancer therapy is vascular endothelial growth factor and its receivers, which play an essential role in tumor-induced angiogenesis. Patent application US2008214465 claims protection for a breast cancer treatment by administering a vascular endothelial growth factor (VEGF) antagonist VEGFR1R2Fc Delta C1 comprising a sequence of fully defined 458 amino acids (SEQ ID NO: 2) [15].

Antibodies with specificity for tumor antigens could provide efficient immunomodulation and selective cytotoxicity for neoplastic cells, as is the case of patent application US2012201752, which claims an isolated antibody or functional fragment which binds an antigenic peptide sequence corresponding to the $\mathrm{N}$-terminal transactivation domain of human forkhead box C1 (FOXC1) [16].

Turning to diagnosis, patent applications US2009232818 and US2010330075 mention antibodies capable of binding to the variable part of an antibody (CDR) or to measure the expression level of S14 [17,18]. Meanwhile, patent documents US2008193938 and US2008305959 refer to predicting the continuation of patient treatment by detecting expression levels of a set of genes or one particular gene (estrogen receptor) $[9,10]$.

In Asia there are 43 patent applications specifically for breast cancer. The priority applications of 30 of these were filed in China, mostly by universities and/or research centers (25), followed by individual assignees (4) and one company. As for the 11 patent applications filed in Japan specifically for breast cancer technologies, which account for $25 \%$ of the patents filed in this country, most of them are held by private Japanese companies, but all the assignees have just one patent. Just two priority patent applications specifically for breast cancer were filed in South Korea, one by a company and the other by a university $[49,50]$.

Unlike the trend seen in the USA, Japan and South Korea, in China $75 \%$ of the patent applications are specifically for breast cancer treatments, and five are also for technologies used in the diagnosis of breast cancer, while another five are for technologies for preventing the disease. There are only two patent applications which target not just breast cancer treatment, but also its prevention and diagnosis. Additionally, it is worth noting that only one of these 30 documents was filed outside China [19]. This means that the technologies described in the 29 other patent documents will only be protected in China, if their patents are granted.

Amongst the 30 priority patent documents filed in China for technologies specifically for breast cancer, $60 \%$ are from Group 1 and make claims for new fusion or other kinds of proteins, toxins [20-25], recombinant peptides (e.g. biosensors [26]) and monoclonal antibodies $[27,28]$, most of them to be used in the production of drugs to treat breast cancer. The remaining $40 \%$, from Group 2, contain patent applications for oligonucleotides [29,30], RNA interference [31], fusion genes [32-33] and vectors [34-36], many to be used in the production of vaccines $[32,33,36]$ and drugs for breast cancer treatment [28,37-40].

All 11 Japanese patent applications are for breast cancer treatment, and four of them [41-44] also address the diagnosis of the disease using monoclonal antibodies, while one is for a drug to prevent breast cancer [42]. The breast cancer treatments that are the subject of the patent claims are: (a) monoclonal antibodies that identify and inhibit the proliferation of cancer cells [45-47], some 
acting in the identification of pre-cancerous stem cells and also the inhibition of genes from these cells [42], and compounds with estrogenic effect, their analogs and their antagonistic inhibitors [48].

One of the two breast cancer-specific patents with priority applications in South Korea claims protection for a drug with RNAi which acts on cancer stem cells [49], while the other is for a specific DNA molecule used in the composition of a drug for breast cancer treatment and diagnostic kits [50].

Amongst the 169 patent applications categorized as relating to breast cancer and other cancers, the highest proportions were for monoclonal antibodies, followed by proteins (see Figure 4, Group 1) and oligonucleotides (see Figure 5, Group 2). One representative example is an US patent application for a new anti-cancer cytotoxic monoclonal antibody, useful for reducing and treating human breast or lung tumor burden [51]. Meanwhile, a Chinese patent application (CN102061285) claims protection for using a nicotinamide adenine dinucleotide (NAD) and NAD hydrogenase (NADH) based drug for killing malignant cells, e.g. kidney cancer cells,

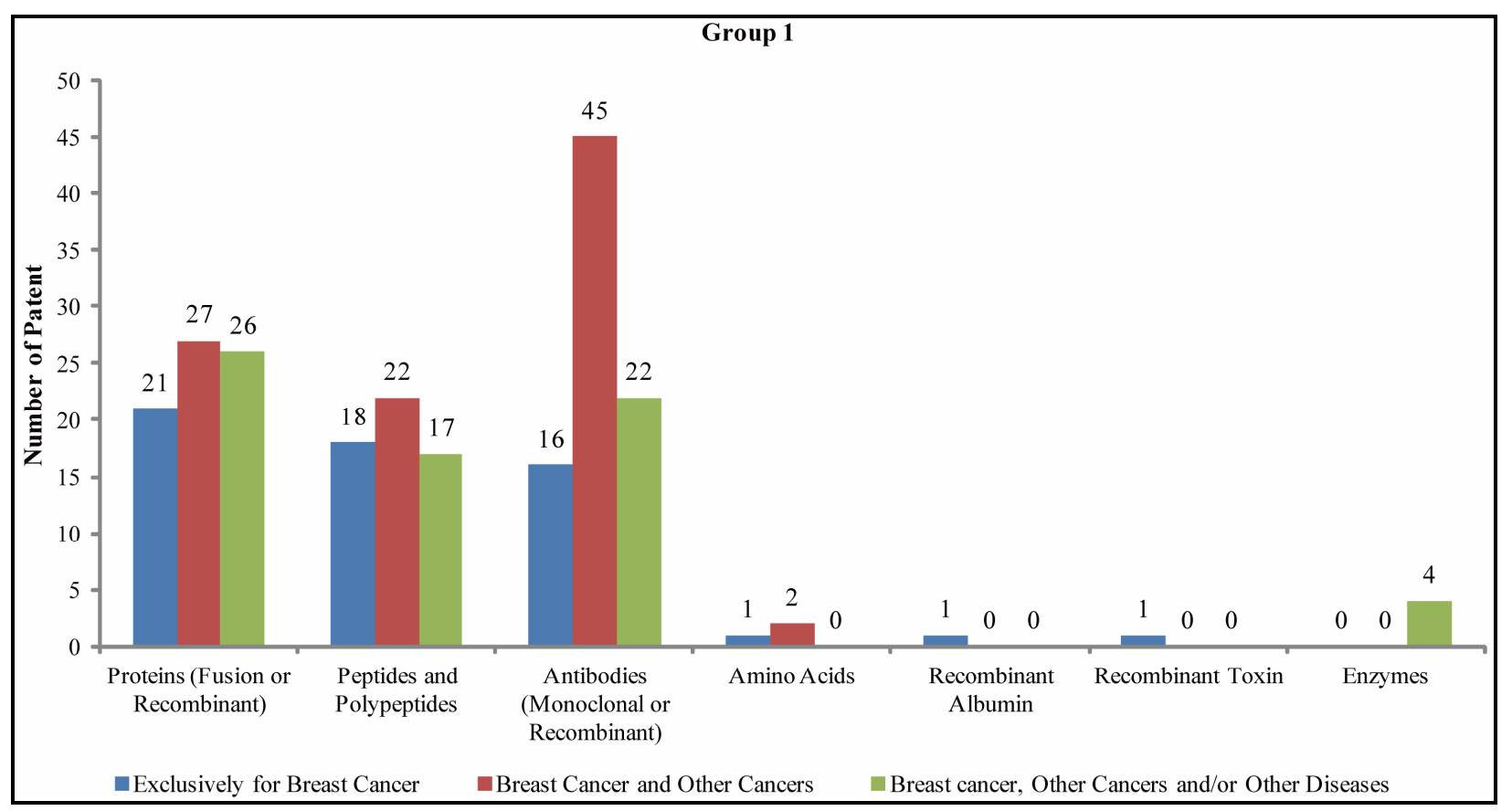

Figure 4. Number of patent documents for Group 1 biotech entities according to the intended application of the technology.

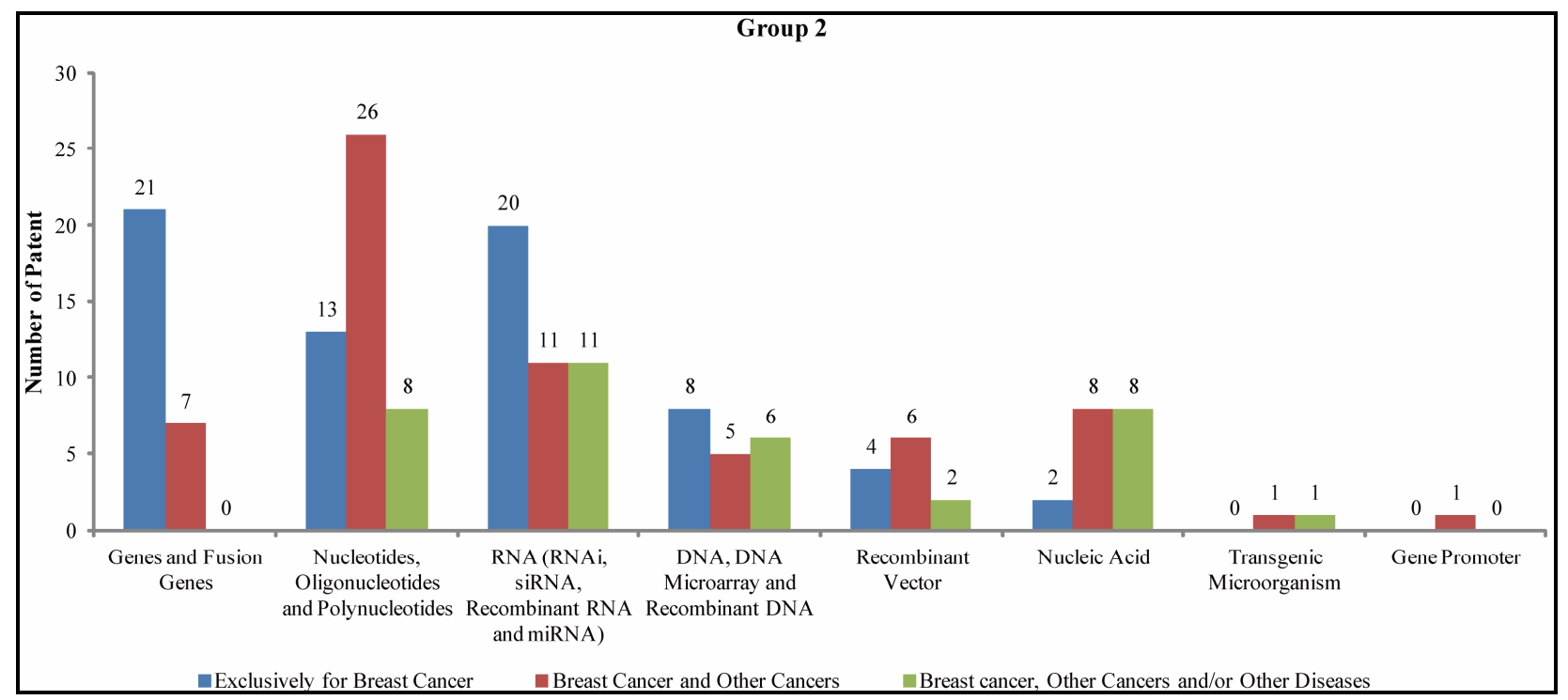

Figure 5. Number of patent documents for Group 2 biotech entities according to the intended application of the technology. 
in a process that involves mixing NAD and NADH powders, and adding the obtained drug to cultured malignant cells [52].

The majority of the 128 patent documents for breast cancer and other diseases were from Group 1, principally proteins and antibodies, while a smaller proportion were for oligonucleotides, nucleic acids, recombinant RNA and microRNA (Group 2). The patent documents are often related to immune system modulation, as they address the treatment of chronic autoimmune diseases or are sometimes related to homeostatic (hormonal) control. Two examples worth citing are: US2012231006 (from Group 1), which involves a new anti-calcium releaseactivated calcium modulator 1 antigen binding protein, useful for treating an immune disorder, a disorder related to venous or arterial thrombus formation, and breast cancer; and CN102307997 (from Group 2), for the modulating function and expression of sirtuin 1 polynucleotide, useful to prevent or treat, e.g. breast cancer, diabetes, obesity, cataract and osteoporosis, and which comprises contacting the cells or tissues with an antisense oligonucleotide [53,54].

\section{Conclusions}

The number of cancer cases around the world continues to rise, especially because of increased life expectancy. Different studies have put forward new treatment techniques, but as cancer is a multifactorial disease, such procedures are not always effective and major research and development effort is required to discover safer and more effective novel treatments for patients. By mining patents in databases, this study was able to highlight R\&D trends in biotechnology for breast cancer treatment, meaning the use of biotech tools to replace chemical entities, such as gene therapy, the use of RNAi and antibodies, fusion or recombinant protein- and peptidebased drugs to target cells more specifically and efficiently.

It is important to stress that many of the findings from recent $R \& D$ of drugs for breast cancer treatment can also be applied to the treatment of other cancers, especially lung cancer, colon cancer and prostate cancer, and also for the treatment of other diseases including diabetes, rheumatoid arthritis, Alzheimer's disease, Huntington's disease, Parkinson's disease, multi-infarct dementia, mixed Alzheimer/multi-infarct dementia and hypothyroidism.

There are clear signs from the patent landscape analyzed here that it is in the United States that the greatest R\&D effort is being put into developing biotech drugs for breast cancer treatment. However, there is also important work being done in Asia, especially China and Japan, where the majority of patent applications are filed by universities and research centers.

\section{Acknowledgements}

The authors thank CAPES (Coordenação de Aperfeiçoamento de Pessoal de Nível Superior) for access to the Derwent database, available at the CAPES Journal Portal (http://www.periodicos.capes.gov.br/).

\section{REFERENCES}

[1] C. L. Canongia, "Model of Strategic Prospection: Synergies between Competitive Intelligence (CI), Knowledge Management (KM) and Foresight (F). A Case Study of the Use of Biotechnology in Drugs for the Treatment of Breast Cancer,” Ph.D. Dissertation, Federal University of Rio de Janeiro, Rio de Janeiro, 2004.

[2] Organization for Economic Co-Operation and Development, "Frascati Manual: Proposed Standard Practice for Surveys on Research and Experimental Development, The Measurement of Scientific and Technological Activities,” OECD Publishing, Paris, 2002.

[3] A. L. Porter and N. C. Newman, "Patent Profiling for Competitive Advantage-Deducing Who Is Doing What, Where, and When,” In: H. F. Moed, et al., Eds., Handbook of Quantitative Science and Technology Research, Springer, The Netherlands, 2004, pp. 587-612.

[4] World Health Organization, International Agency of Research on Cancer, "GLOBOCAN," 2008.

http://globocan.iarc.fr/factsheets/populations/factsheet.asp ?uno $=900$

[5] Instituto Nacional de Cancer (INCA), “Tipos de Cancer," 2013.

http://www.inca.gov.br/wps/wcm/connect/tiposdecancer/s ite/home/mama

[6] World Health Organization, International Agency of Research on Cancer, “GLOBOCAN 2008, IARC,” 2010. http://www.who.int/mediacentre/factsheets/fs297/en

[7] National Cancer Institute, “General Information about Breast Cancer,” 2013.

http://www.cancer.gov/cancertopics/pdq/treatment/breast/ Patient/page1

[8] World Health Organization, "Genomics and World Health. Report of the Advisory Committee on Health Research," 2002. http://www.who.int/en

[9] Y. Kun and P. Tan, "Materials and Methods Relating to Breast Cancer Classification,” US Patent No. 2008193938, 2008.

[10] Y. Wang, J. X. Yu, Y. Jiang and F. Yang, “Laser Microdissection and Microarray Analysis of Breast Tumors Reveal Estrogen Receptor Related Genes and Pathways," US Patent No. 2008305959, 2008.

[11] H. Y. Chang and R. A. Gupta, "Linc RNAs in Cancer Diagnosis and Treatment,” US Patent No. 2012004278, 2012.

[12] Y. Nakamura, T. Katagiri and S. Nakatsuru, "Method of Diagnosing Breast Cancer,” US Patent No. 2012010090, 2012.

[13] R. M. Crooke and M. J. Graham, "Effects of Apolipoprotein B Inhibition on Gene Expression Profiles,” US Patent 
No. 2010331390, 2010.

[14] Y. Paterson, P. Maciag, M. Seavey and S. Ferrone, "Compositions Comprising HMW-MAA and Fragments Thereof, and Methods of Use Thereof,” US Patent No. 2009202587, 2009.

[15] J. M. Cedarbaum, "Method of Administering and Using VEGF Inhibitors for the Treatment of Human Cancer," US Patent No. 2008214465, 2008.

[16] X. Cui, "FOXC1 Antibodies and Methods of Their Use," US Patent No. 2012201752, 2012.

[17] W. B. Kinlaw, "Prognosis and Treatment of Breast Cancer,” US Patent No. 2009232818, 2009.

[18] C. Esslinger, S. Kuenzle, I. Abela, A. Zippelius, D. Jaeger, A. Knuth, R. Nitsch, H. Moch and N. Goebels, "Monoclonal Human Tumor-Specific Antibody," US Patent No. 2010330075, 2010.

[19] S. Chen and B. Zhu, "Nano-Scale Artificial Oil Body for Targeted Drug Delivery System Detection and Treatment," Chinese Patent No. 102743327, 2012.

[20] S. Y. Sun, "FK Gene, Coding Protein and Application Thereof,” Chinese Patent No. 101058604, 2007.

[21] S. Y. Sun, "Breast Cancer Relevant P69 Gene, Coding Protein and Application Thereof," Chinese Patent No. 101058808, 2007.

[22] R. Niu, L. Zhang, D. Wang, Y. Shi, X. Wei, Y. Yang, J. Huang, Y. Niu, B. Sun and X. Hao, "Human Breast Cancer Resisting Recombination Immunotoxin M4G3/ ScFv-PE40,” Chinese Patent No. 101148475, 2008.

[23] X. Yao, F. Wang, E. Song, H. Deng, D. Wang, J. Chen, Z. Dou and X. Ding, "Acceptor Protein, and Coding Gene and Application Thereof,” Chinese Patent No. 102475890, 2012.

[24] S. Y. Yi, "Breast Cancer Related Gene DREE, Its Coded Protein and Uses,” Chinese Patent No. 1807455, 2006.

[25] W. W. Jiang, "scFvC6.5-s Trail Fusion Gene and Protein, and Its Preparation,” Chinese Patent No. 1865445, 2006.

[26] S. Wu and J. Gong, "Nucleic Acid Aptamer with High Specificity and High Affinity to Human Breast Carcinoma Tissue, Preparation Method and Application Thereof," Chinese Patent No. 101148666, 2008.

[27] S. Li, Y. Wang, J. Pan, Q. Zhao and H. Wang, "Humanized Breast Cancer Antigen and Antibody Thereof," Chinese Patent No. 101962405, 2011.

[28] Q. Wei, X. Cao, Y. Jun and Y. Lu, "Human Prolactin Receptor Antibody and Application Thereof," Chinese Patent No. 102250244, 2011.

[29] Y. Jiang, N. Zhang and Z. Xie, "Medicament for Curing Breast Carcinoma and Special Antisense Oligonucleotide Therefor," Chinese Patent No. 101275134, 2008.

[30] J. Luo, X. Wang, M. Liu, X. Tang and R. Jin, “GPR116 (G-Protein Coupled Receptor) Gene, Receptor Protein Coded by Same and Application of the GPR116 Gene,” Chinese Patent No. 102041259, 2011.

[31] E. Song, J. Chen and X. Yao, “Application of PITPNM3 Gene in Preparing Medicine for Inhibiting Breast Cancer Invasion and Transfer," Chinese Patent No. 102160895, 2011.
[32] S. Yuan, Z. Shi, W. Han, Y. Zhang, R. Ling, N. Li and T. Wang, "Recombinant BCG Vaccine Based on Human MUC1 Repetitive Sequence and GM-CSF Fusion Expression,” Chinese Patent No. 101575607, 2009.

[33] N. Guo, Z. Xie and M. Shi, "Heterogenetic Antigen-Fc Fusion Protein Capable of Inducing Antitumor Immunity of Organism and Application Thereof," Chinese Patent No. 101638440, 2010.

[34] Y. Liu and W. Zhang, "A Series of Recombinant AdenoAssociated Viral Vectors, Construction Methods and Uses Thereof,” Chinese Patent No. 102268458, 2011.

[35] Z. X. Li, "Method for Coustructing shRNA Expression Carrier for Inhibiting N-Acetylglucosamine Transferase V and Its Use,” Chinese Patent No. 1936012, 2007.

[36] W. T. Wang, "Construction of HER2/neu mRNA in Vitro Transcription Vector and Use Thereof,” Chinese Patent No. 1966684, 2007.

[37] Y. Ge, X. Zhang, J. Zhang, L. Hou and M. Xue, "KDR siRNA and Application Thereof," Chinese Patent No. 101215563, 2008.

[38] J. Zhang, X. Ding, J. Zhou, S. Xiang, X. Hu and M. Han, "SiRNA for Inhibiting Human KCTD1 Gene Expression and Use Thereof in Pharmacy," Chinese Patent No. 101481688, 2009.

[39] M. Li, L. Jun, J. Cai, Y. Huang, J. Wu and J. Yuan, “Molecular Marker HSA-miR-374a of Breast Carcinoma and Application Thereof,” Chinese Patent No. 101633922, 2010.

[40] J. Dong, L. Fu, D. Su, X. Wu and Z. Zhu, "Breast Cancer Related Gene C10RF64 and Application Thereof,” Chinese Patent No. 101701220, 2010.

[41] T. Nagahata and M. Emi, "Material for Suppressing SEPT11 Gene Expression,” Japanese Patent No. 254830, 2006.

[42] N. Goto, M. Murohashi, H. Yuya, T. Isagawa and M. Kuroda, "Test Method for Predicting Recurrence of Solid Cancer and Recurrence Prophylactic," Japanese Patent No. 2010178650, 2010.

[43] S. Watanabe, M. Ito, J. Imai, T. Otake, T. Fujita and Y. Sakai, "Method for Discriminating Subtype of Breast Cancer,” Japanese Patent No. 2012085554, 2012.

[44] S. Watanabe, M. Ito, J. Imai, T. Otake, T. Fujita and Y. Sakai, "Method for Diagnosis of Breast Cancer," Japanese Patent No. 2012085556, 2012.

[45] T. Nagahata and M. Emi, "RA13 Gene Expression Inhibitor,” Japanese Patent No. 2005287456, 2005.

[46] H. Nakatake and C. Nozaki, "Inhibitory Antibody against Malignant Tumor Cell Growth,” Japanese Patent No. 2005206508, 2005.

[47] Y. Nakamura, H. Yasuoka, M. Tsujimoto, R. Goto, Z. Totsuka, K. Momiyama, K. Kakudo and N. Takami, “Therapeutic Agent for Highly Malignant Breast Cancer," Japanese Patent No. 2008110975, 2008.

[48] Y. Sugimoto, S. Tsukahara and Y. Imai, “Anticancer AgentResistance Overcoming Agent,” Japanese Patent No. 2006069910, 2006.

[49] C. W. Kim and J. Y. Jang, "Method for Treating Breast Cancer by Decreasing the Expression of Adenine Nucleotide Translocator 2 mRNA,” Korean Patent No. 2012- 
0095263, 2012.

[50] D. K. Lee and H. S. Kang, "Nucleic Acid Aptamer Capable of Specifically Binding to HER-2-Overexpressing Breast Cancer Cell or Tissue and Use Thereof,” Korean Patent No. 20110086433, 2011.

[51] D. S. F. Young, H. P. Findlay, S. E. Hahn and L. M. Cechetto, "Cancerous Disease Modifying Antibodies," US Patent No. 2009104115, 2009.

[52] W. Yin, W. Xia, Y. Ma, C. Zhao, Y. Hong, J. Han and H. Chen, "Application Method for Medicament Based on
NAD $<+>$ and NADH," Chinese Patent No. 102061285 , 2011.

[53] H. Q. Nguyen, F. Lin, X. Bi, H. J. Mcbride and S. S. Hu, "Anti-Oral Antigen Binding Proteins and Uses Thereof," US Patent No. 2012231006, 2012.

[54] J. Collard, O. K. Sherman, C. Coito and B. Leon, "Treatment of Sirtuin 1 (SIRT1) Related Disease by Inhibition of Natural Antisense Transcript to SIRT1,” Chinese Patent No. 102307997, 2012. 